\title{
Scale-Dependent Browsing Patterns on Canada Yew (Taxus canadensis) by White-Tailed Deer (Odocoileus virginianus)
}

\author{
Steve K. Windels ${ }^{1}$ and David J. Flaspohler ${ }^{2}$ \\ ${ }^{1}$ Voyageurs National Park, National Park Service, International Falls, MN 56649, USA \\ ${ }^{2}$ School of Forest Resources and Environmental Science, Michigan Technological University, Houghton, MI 49931, USA \\ Correspondence should be addressed to Steve K. Windels; steve_windels@nps.gov
}

Received 3 June 2013; Accepted 17 September 2013

Academic Editor: Friedrich Reimoser

Copyright @ 2013 S. K. Windels and D. J. Flaspohler. This is an open access article distributed under the Creative Commons Attribution License, which permits unrestricted use, distribution, and reproduction in any medium, provided the original work is properly cited.

\begin{abstract}
Canada yew (Taxus canadensis) is a clonal shrub that forms discrete patches and was formerly an important component of forest understories in much of northeastern North America. Following Euro-American settlement, Canada yew has been extirpated or reduced in abundance throughout much of its former range, particularly in the USA; winter browsing by white-tailed deer (Odocoileus virginianus) has been implicated as responsible for much of its decline. Little is known about the factors affecting deer browsing intensity on Canada yew. We examined factors related to browsing intensity on Canada yew across three spatial scales in 29 forest stands in Michigan, USA. Browsing intensity on stems was related principally to two factors acting simultaneously across multiple spatial scales. Browsing intensity was negatively related to amount of Canada yew at the scale of the forest stand and negatively related to distance from the edge of Canada yew patches, effectively creating refugia from browsing. The browsing patterns we observed suggest that yew exists in two alternate stable states: (1) as loose aggregations of small stems or (2) large, dense patches of large stems. The implications of changes in deer density or snow cover to the probability of local persistence of Canada yew are discussed.
\end{abstract}

\section{Introduction}

It is well accepted that large mammalian herbivores make foraging decisions based on interactions with resources across several spatial scales [1-3]. The collective result of foraging decisions made by herbivores at the plant individual or population level can ultimately influence plant populations, plant community structure, and ecosystem processes [3-6]. Therefore, it is important to understand patterns in ungulate foraging at multiple spatial scales to allow management and conservation efforts for affected plants to be scaled appropriately $[2,7]$.

Opportunities to better understand spatially dependent browsing patterns by ungulates emerge with Canada yew (Taxus canadensis), a declining species that is sensitive to browsing. Also known as ground hemlock or American yew, Canada yew is a monoecious, evergreen shrub native to the mixed conifer-hardwood forests of the northeastern United States and southeastern Canada [8]. Canada yew has garnered interest as a nontimber forest product over the last 20 years because of its pharmaceutical properties [9, 10]. Prior to Euro-American settlement, it was likely a major ground cover component in late-successional mesic forests of this region [8]. Canada yew has been extirpated or its abundance significantly reduced from most of its range in the US Several factors are often implicated in this decline, including the conversion of mid-to-late-successional mesic forest habitats to agriculture and short-rotation forestry and intense slash fires following the logging of primary forests. Canada yew is considered one of the most highly preferred winter forage items for white-tailed deer (Odocoileus virginianus) [11, 12]; therefore erupting populations of deer following the large-scale disturbances of the late 1800s and early 1900s are also often implicated in the decline of yew $[8,11,13,14]$. White-tailed deer densities are currently at least 2-4 times greater in the Great Lakes states than at the time of European settlement [15], and high deer abundance continues to remain one of the primary 


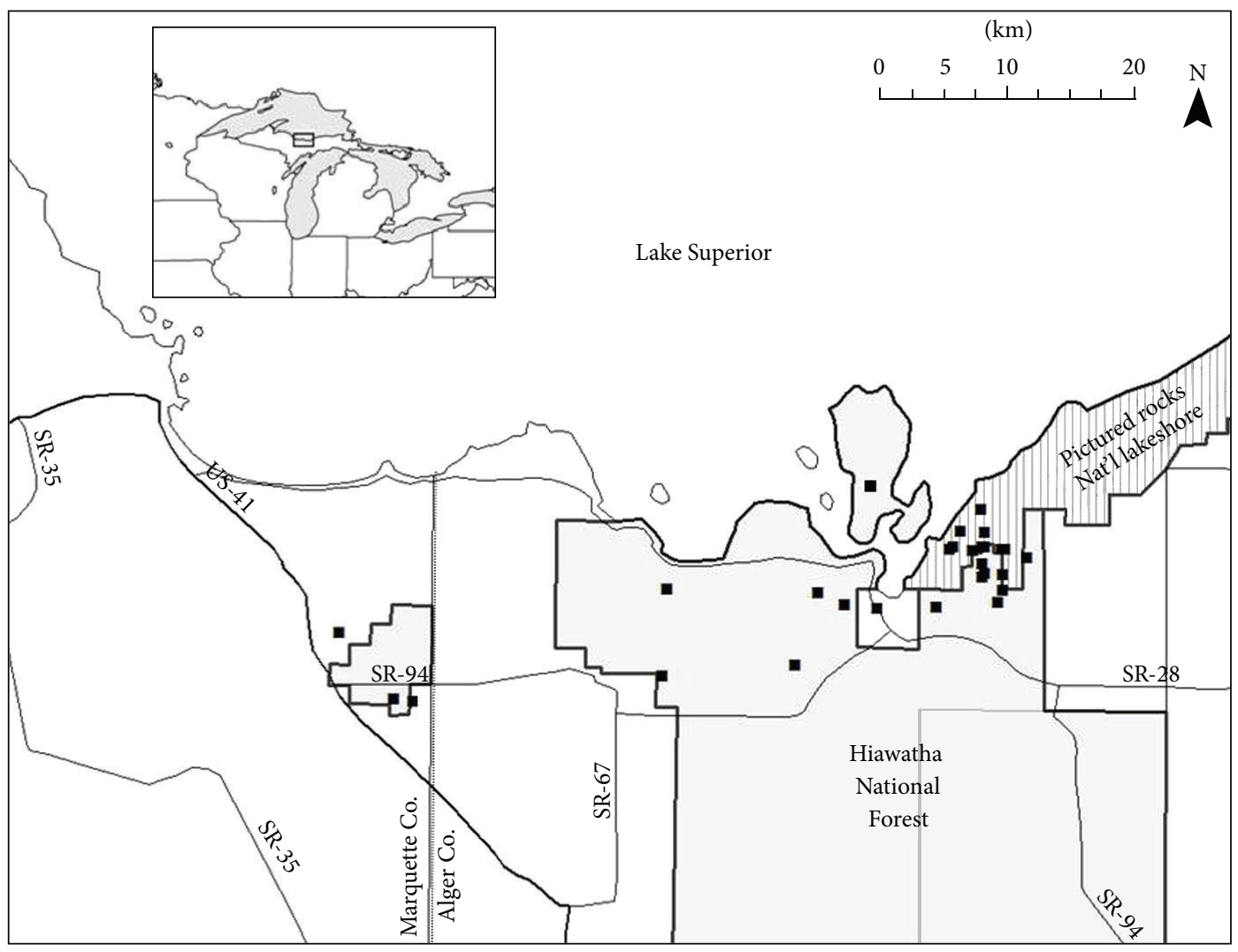

FIGURE 1: Distribution of study sites (black squares) in Marquette and Alger counties, Michigan, USA. Inset shows location of study area in relation to the Great Lakes.

factors in the continued decline in Canada yew in the region $[5,8]$.

But how does white-tailed deer browsing specifically lead to reductions in Canada yew abundance and distribution? As we suggest above, increases in deer density should result in an increase in browsing pressure on Canada yew, for a given yew abundance. Further, if annual removal of twigs by deer exceeds annual growth, then a decline in plant abundance should result. More specifically, though, the impacts of deer browsing on Canada yew at large scales are the sum of impacts that occur at finer spatial scales, such as decisions by deer on which Canada yew patches to visit or which stems to browse.

Production of new stems (ramets) by sexual reproduction by Canada yew appears rare [8]. Instead Canada yew reproduces predominantly by layering whereby arching lateral branches are pressed to the ground and take root, resulting in a spreading growth form that often produces roughly circular-shaped patches comprised of dense tangles of intertwining stems; this patchy growth form is especially evident in high-density areas with large individual stems [13]. The unique reproductive strategy of Canada yew results in a highly patchy distribution across most spatial scales, for example, within its North American range, between forest stands, or within forest stands [8]. This patchiness creates differences in abundance of Canada yew at various spatial scales that may affect the likelihood of a deer browsing an individual stem. Deer may also more preferentially browse on the exterior of patches as the dense stems on the interior may deter movements.

Despite many anecdotal accounts, little is known about browsing patterns by white-tailed deer on Canada yew in the Great Lakes region, a historically important portion of Canada yew's range. Specifically, it is unknown what stem, patch, and stand-level factors affect browsing intensity on Canada yew. Here, we attempt to identify scale-dependent factors influencing browsing by deer on Canada yew. This information is needed to assist in the conservation and management of Canada yew in areas of its range that overlap with white-tailed deer.

\section{Methods}

2.1. Study Area. Our study was conducted in Marquette and Alger Counties, Michigan, USA (Figure 1). Vegetation is predominantly upland forest dominated by the deciduous sugar maple (Acer saccharum), yellow birch (Betula alleghaniensis), and American beech (Fagus americana) but also contains patches of codominant eastern hemlock (Tsuga canadensis), eastern white pine (Pinus strobus), balsam fir (Abies balsamea), and white spruce (Picea glauca). Climate is greatly moderated by Lake Superior, with cool summers and mild winters with heavy snowfall. Average (1949-2001) winter snowfall (November-April) in the study area is $353 \mathrm{~cm}$ and average maximum snow depth, typically reached between 


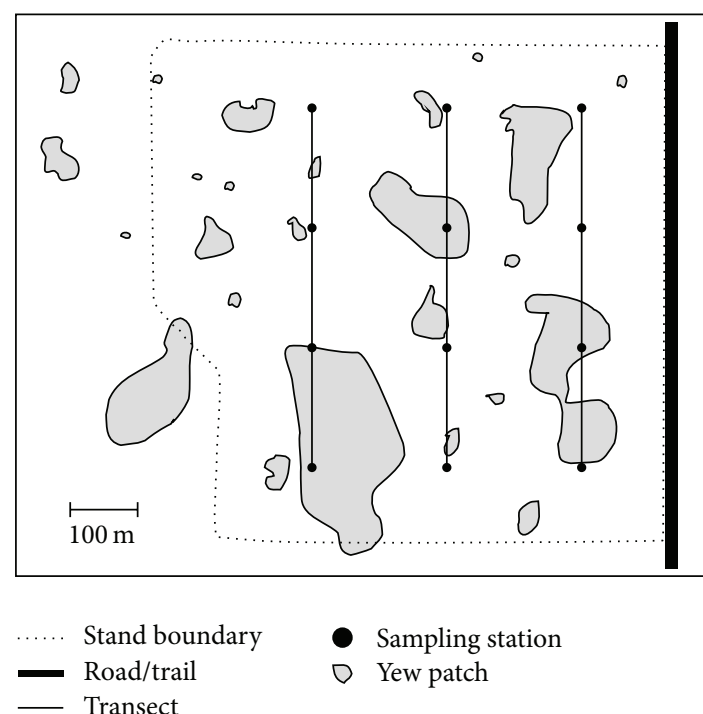

FIGURE 2: Typical arrangement of sampling transects and stations in relation to patches of Canada yew for 29 forested stands sampled in Marquette and Alger counties, Michigan, USA.

mid-February to Mid-March, is $114 \mathrm{~cm}$ [16]. Total winter snowfall and maximum snow depth were $\sim 10 \%$ below average in 1998-1999 and 1999-2000 and >25\% above average in 20002001 and 2001-2002 [16]. Winter deer densities in the study area are very low $\left(<2 / \mathrm{km}^{2}\right)$; under normal snow conditions most deer migrate out of the study area to traditional winter deer yards outside of the Lake Superior Watershed [17]. Snowshoe hare (Lepus canadensis) densities are low and moose (Alces alces) are rare in the study area; therefore browsing on Canada yew in the study area is almost done exclusively by white-tailed deer and is limited to the winter months.

Twenty-nine (29) mesic northern/mixed hardwood forest stands on moderately to well-drained sandy or sandy loam soil were selected for study (Figure 1). A stand was defined as having a relatively uniform vegetation composition and stand history as determined from a combination of aerial photos, topographic maps, stand compartment maps, and groundtruthing. Stands were selected primarily to represent the range of Canada yew ground cover in the region: low (1-15\% ground cover), medium (15-30\%), and high (>30\%). Stands were also limited to those $>70 \%$ tree canopy cover. Fifteen of the stands were sampled in 2001 and the remaining 14 in 2002. Twenty-three of these stands were managed for sawtimber at the time of sampling, that is, selection harvest to reduce tree basal area to approximately $16 \mathrm{~m}^{2} /$ ha every $10-15$ years; the remaining six were within protected areas free of timber harvest for at least 30 years.

Within each stand, sampling stations were systematically established along equally spaced transects to ensure uniform coverage of the site (Figure 2). Stations were spaced $>175 \mathrm{~m}$ from each other and $>100 \mathrm{~m}$ from roads and site boundaries to minimize edge effects. The number of stations varied from 8 to 18 , depending on the area and shape of the stand.
2.2. Vegetation Measurements. Because Canada yew reproduces vegetatively and below-ground connections between ramets (stems) deteriorate after a few years, it is extremely difficult to delineate genets (genetic individuals). Therefore, the ramet was selected as the basic sampling unit and defined as an emergent stem not connected to neighboring stems at a soil depth of $2 \mathrm{~cm}$ [14]. A nearest neighbor method was used to collect data on five Canada yew ramets at each station. Starting at the center of the sampling station, the nearest stem was selected and the following measurements were taken on each: distance from start point to stem; total stem length (from $2 \mathrm{~cm}$ above soil to terminal leader); maximum stem height perpendicular to the ground; whether the stem was broken; whether the stem was live or dead. Each live stem was also scored based on a visual assessment of the proportion of annual growth browsed by deer during any of the previous few winters (i.e., 1-3 winters) from the time of sampling $(1=<5 \%$ twigs browsed, $2=6-25 \%, 3=26-50 \%, 4=51-75 \%$, $5=76-95 \%, 6=>95 \%)$. This scoring system was used for two reasons: (1) consistently differentiating browsing evidence between the most recent winter and previous winters can be problematic for Canada yew [18], and (2) by using a composite measure of browsing over three consecutive winters we compensated for any annual differences in winter deer use a site may have received; that is, we assume that each site should have received an approximately equal amount of deer use over the three years combined. Although winter browsing by snowshoe hares on Canada yew is relatively rare in the Great Lakes region [18], the roughly crushed stems from deer browsing are easily differentiated from the clean, angular bite characteristic of snowshoe hares.

For each cluster of sampled stems, slope, aspect, and whether or not they were part of a Canada yew patch were recorded. A patch was defined as a $>1 \mathrm{~m}$ diameter cluster of stems at a density greater than $\approx 15 / \mathrm{m}^{2}$. Distance $(\mathrm{m})$ to the nearest patch edge was recorded for stems within patches. Sampling stations where Canada yew stems were not recorded were omitted from analysis leaving 24 stands with at least one sampling station where Canada yew was detected. Analyses were further limited to those clusters containing at least 3 live stems. Means for each of these clusters were determined for stem length and browsing score.

All trees ( $\geq 3 \mathrm{~cm} \mathrm{dbh}$ ) were identified to species, counted, and classified according to 8 size classes (based on dbh) within a 0.02 ha plot at each station to estimate basal area. Canopy cover of deciduous and coniferous trees was estimated with an ocular tube at 21 points along a transect bisecting the station. Canopy cover at each station was then designated as deciduous ( $<25 \%$ canopy coverage by conifers) or mixed $(\geq 25 \%)$.

Areal coverage of Canada yew within each stand was estimated from a uniform grid of $11 \mathrm{~m}$ radius plots spaced along and in between vegetation station sampling transects such that each stand had a sampling station: $11 \mathrm{~m}$ plot ratio of $\sim 1: 3$. Cover of Canada yew within $11 \mathrm{~m}$ plots was visually estimated to the nearest $1 \%$ and mean percent cover within each stand was calculated. 
2.3. Deer Pellet Counts. To test whether stands received similar browsing pressure, in May 2002, $3 \mathrm{~m}$ radius plots were systematically located throughout each stand (range $=22-83$ ) and the number of white-tailed deer pellet-groups deposited that winter was counted in each plot. Pellet-groups deposited in winter can be easily differentiated in spring from those deposited during the previous summer or winter periods (i.e., pellets $>7$ months old), and the number of pellet-groups/ $400 \mathrm{~m}^{2}$ sampled can be used as a relative index of local winter deer abundance [17]. Based on various reported defecation rates, Potvin et al. [17] estimated that 6.75 pellet-groups/ $400 \mathrm{~m}^{2}$ sampled were equivalent to $2.3-5.8 \mathrm{deer} / \mathrm{km}^{2}$.

2.4. Statistical Analysis. Our study is an observational one and is therefore best suited for analysis with an informationtheoretic approach to model selection [19]. We developed nine a priori models composed of independent variables that might influence browsing intensity based on a literature review, personal observations, and pilot data from September 2000 from a separate study area $>200 \mathrm{~km}$ distant. Models incorporated three spatial scales of browse selection: (a) at the scale of clusters of individuals stems $(<0.001 \mathrm{ha})$, (b) at an intermediate scale that incorporates spatial heterogeneity in vegetation characteristics within each stand ( $~ 0.01-0.1 \mathrm{ha})$, and (c) at the scale of individual stands (20-50 ha).

Models 1-4 (Table-Models) focused on two variables at the smallest scale, and included combinations of mean stem length (LENGTH) and patch location (LOC). Stem length is related to both apparency to herbivores (e.g., taller stems are more likely to be seen, easier to access, and remain above snow pack) and biomass [18]. White-tailed deer may be reluctant to enter dense patches of Canada yew because of increased travel costs [20,21]. Further, severity of browsing on Canada yew may be either positively or negatively related to the amount of conspecific browse biomass available nearby [22]. To simplify interpretation of the models, clusters of stems were placed into one of three patch location categories for analysis: "No Patch" (stems not in a defined patch); "Edge" ( $<1 \mathrm{~m}$ from edge of defined patch); and "Interior" ( $>1 \mathrm{~m}$ from edge of defined patch). We justified grouping clusters into the "interior" category after univariate plots suggested that the effect of distance from patch edge on browsing intensity was relatively uniform for values from $\geq 1 \mathrm{~m}$ from the edge (range $=1-25 \mathrm{~m}$ ).

Models 5-8 focused on three intermediate-scale habitat variables that may affect browsing intensity on stems: slope/aspect (SLOPE), percent canopy cover (CANOPY), and proportion of canopy comprised of conifer species (CONIFER). These variables may affect browsing by: (1) reducing snow cover (e.g., north-facing slopes generally retain more snow than south-facing slopes, and conifer-dominated canopies intercept more snow than deciduous-dominated canopies), or (2) changing the amount of photosynthetically active radiation reaching the understory and therefore affecting nutritional quality of browse (e.g., greater canopy cover is negatively related to amount of sunlight and carbon content in browse, and north-facing slopes receive less sunlight than south-facing slopes). Stachowicz and Allison [14] documented higher browsing rates on Canada yew stems on south-facing slopes and under deciduous canopies. Model 9 evaluated the influence of the total amount of Canada yew browse available within a stand, that is, percent Canada yew cover (YEWCOV), on browsing intensity of individual clusters. Amount of Canada yew at the scale of a deer's home range (or portion thereof) could affect selectivity of browsing by deer (e.g., [23]). Further, there may be a dilution effect in that for a given number of deer, browsing (or probability of browsing) is spread over a greater number of stems as amount of Canada yew increases [22]. A global model containing all of the variables and selected interactions was also included in the model set [19].

Each of the nine models was fit to mean cumulative browsing score for each cluster using a generalized linear model with normal distribution (PROC GENMOD) using SAS 9.1 (SAS Institute, Cary, North Carolina). We used the generalized estimating equations method in GENMOD because it allowed us to account for the nonindependence of clusters of stems within a stand, that is, that clusters within a stand were more likely browsed by the same individual deer than for clusters between stands. Log-likelihood estimates generated by GENMOD for each model were used to calculate Akaike's Information Criterion (AIC) [19]. To account for overdispersion in the data, the quasi-likelihood AIC (QAIC) was used, derived by dividing AIC by an approximated variance inflation factor $\left(\widehat{c}\right.$; the $X^{2}$ statistic divided by the degrees of freedom of the global model). We also used the small sample size adjustment, $\mathrm{QAIC}_{c}$, due to an $n / K$ ratio $<40$ [19]. The model(s) with the smallest $\mathrm{QAIC}_{c}$ value are considered the most parsimonious. We then calculated $\triangle \mathrm{QAIC}_{c}$ (the difference between $\mathrm{QAIC}_{c}$ of each model and the best model) and $\mathrm{QAIC}_{c}$ weights (weight of evidence calculated by rescaling $\triangle$ QAIC $_{c}$ scores such that all weights add to 1). Models with $\Delta \mathrm{QAIC}_{c}<2.0$ are considered equally plausible given the data [19]. Variable importance weights were calculated according to Burnham and Anderson [19].

\section{Results}

A total of 237 Canada yew stem clusters were sampled in 24 stands. Two hundred sixteen (216) clusters had at least 3 live stems, and, of these, 208 clusters were included in the model selection analysis due to missing data. Cover of Canada yew (from $11 \mathrm{~m}$ radius plots) at the 24 stands ranged from 0.0 to $54.4 \%$ (Table 1). At two sites (CWC and Miners Control) no Canada yew was recorded within the $11 \mathrm{~m}$ radius plots but a few small, isolated clusters of stems were located outside of plots. Mean browsing score from clusters of sampled stems ranged from 1.4 to 6.0 across all sites (Table 1 ).

Browsing intensity, as measured by mean cumulative browsing score, tended to decrease as stem length, amount of conifer in canopy, and percent Canada yew cover increased (Figures 3(a), 3(e), and 3(f)). Browsing intensity was greatest for stems not in discrete patches ("No Patch") and least for stems $>1 \mathrm{~m}$ from the edge of patches ("Interior"; Figure 3(f)). Browsing intensity appeared similar between slope/ aspect categories (Figure 3(c)). Dead Canada yew stems were unevenly distributed among the three patch location 


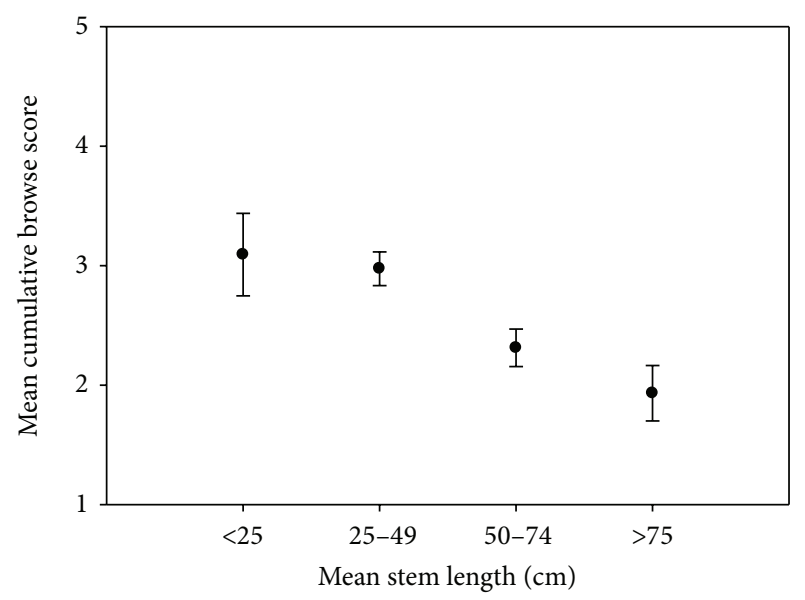

(a)

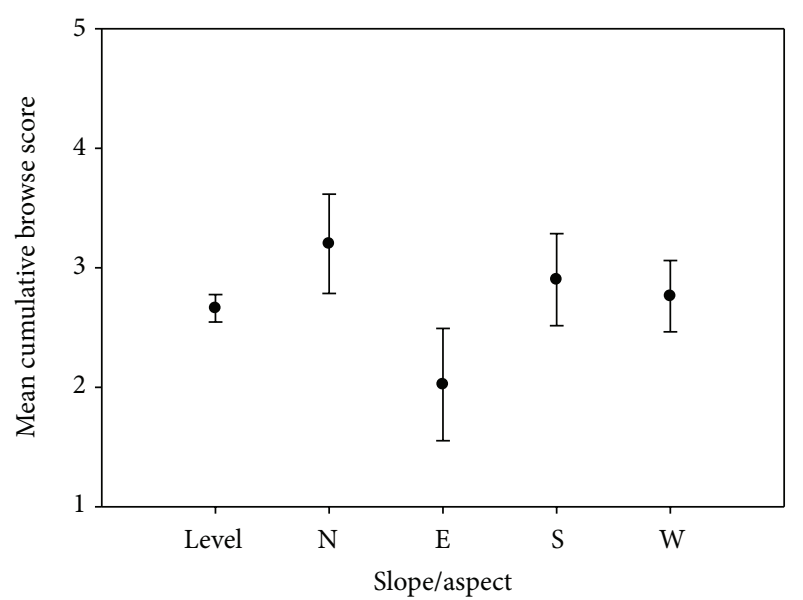

(c)

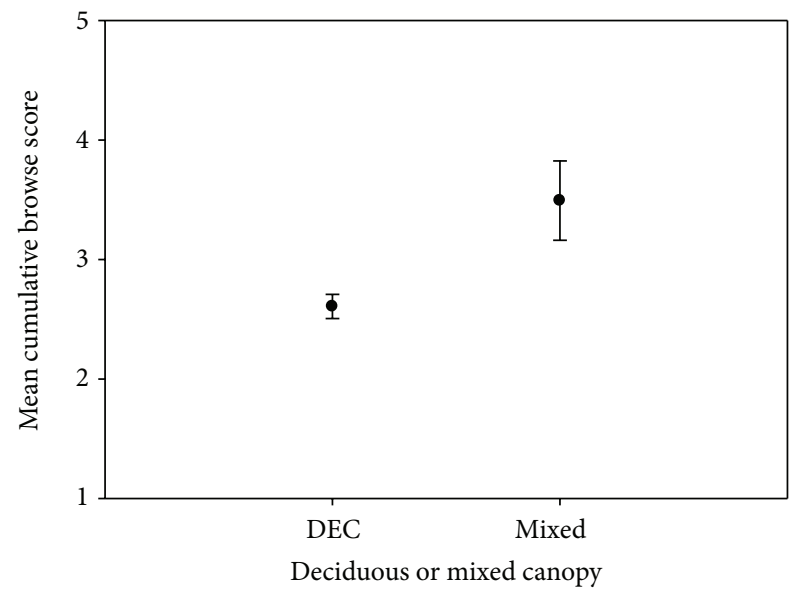

(e)

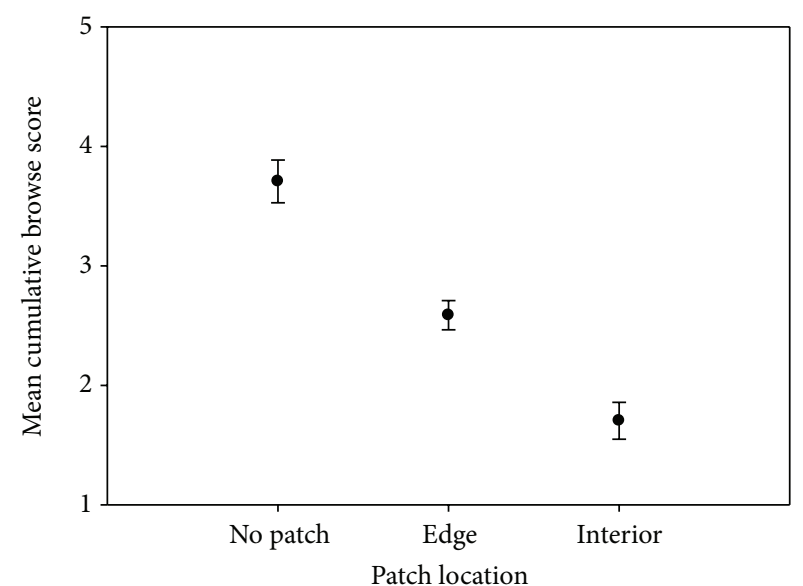

(b)

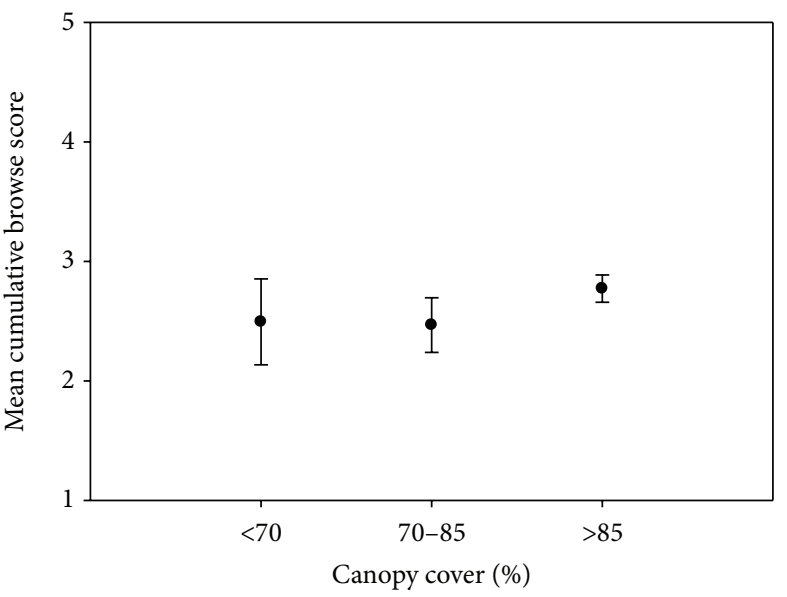

(d)

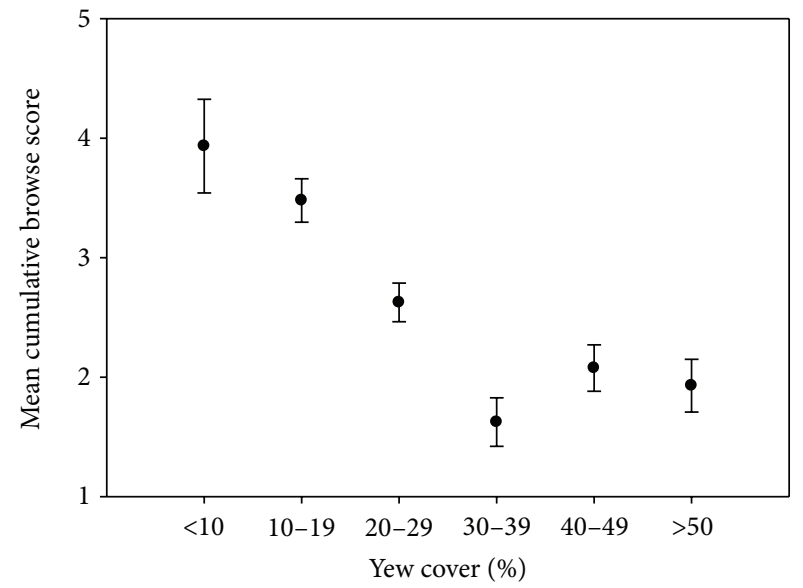

(f)

FIGURE 3: (a-f) Mean cumulative browsing score $( \pm 1$ SE) for clusters of Canada yew stems in relation to various predictor variables from 24 stands in Marquette and Alger counties, MI, 2001-2002. Cumulative browse scores were based on the proportion of twigs browsed by deer during the previous three winters for each stem in a cluster $(1=<5 \%$ twigs browsed, $2=6-25 \%, 3=26-50 \%, 4=51-75 \%, 5=76-95 \%, 6=$ $>95 \%$ ). Predictor variables were: (a) Mean length $(\mathrm{cm})$ of individual Canada yew stems; (b) Location of stems in relation to Canada yew patch edge: No Patch $=$ stems that do not form a discrete patch, Edge $=$ stems $<1 \mathrm{~m}$ from the edge of the patch, and Interior $=$ stems $\geq 1 \mathrm{~m}$ from the edge of the patch; (c) slope and aspect of the site surrounding the Canada yew stems; (d) percent forest canopy cover of the site surrounding the Canada yew stems; (e) composition of forest surrounding the Canada yew stems (DEC $=<25 \%$ conifer, MIXED $=\geq 25 \%$ conifer); (f) percent Canada yew cover in the forest stand, based on $11 \mathrm{~m}$ radius plots. See Section 2 for additional details about predictor variables. 
TABLE 1: Characteristics of 24 forested stands sampled for Canada yew browse in 2001-2002 in Marquette and Alger counties, Michigan, USA. Only those stands with at least one cluster of $\geq 3$ live stems were included in model selection analyses and are shown below.

\begin{tabular}{|c|c|c|c|c|c|c|c|c|c|}
\hline \multirow[b]{2}{*}{$\begin{array}{l}\text { Stand } \\
\text { name }\end{array}$} & \multirow[b]{2}{*}{$\begin{array}{l}\text { Year } \\
\text { sampled }\end{array}$} & \multirow[b]{2}{*}{$\begin{array}{l}\text { Mgmt. } \\
\text { status }\end{array}$} & \multirow[b]{2}{*}{$\begin{array}{l}\text { Mean } \\
\text { canopy } \\
\text { cover }(\%)\end{array}$} & \multirow{2}{*}{$\begin{array}{l}\text { Decid. } \\
\text { basal } \\
\text { area } \\
\left(\mathrm{m}^{2} / \mathrm{ha}\right)\end{array}$} & \multirow{2}{*}{$\begin{array}{l}\text { Conifer } \\
\text { basal } \\
\text { area } \\
\left(\mathrm{m}^{2} / \mathrm{ha}\right)\end{array}$} & \multirow[b]{2}{*}{$\begin{array}{l}\text { Mean } \\
\text { yew } \\
\text { cover (\%) }\end{array}$} & \multicolumn{3}{|c|}{ Yew stems } \\
\hline & & & & & & & $N^{b}$ & $\begin{array}{c}\text { Mean } \\
\text { cumulative } \\
\text { browse score }\end{array}$ & $\begin{array}{l}\text { Mean stem } \\
\text { length }(\mathrm{cm})\end{array}$ \\
\hline CWC & 2001 & $\mathrm{P}$ & $92.6 \pm 2.8$ & 40.0 & 0.0 & $0.0 \pm 0.0$ & 1 & $6.0 \pm \mathrm{na}$ & $19.2 \pm$ na \\
\hline Section 33 & 2001 & M & $86.3 \pm 6.3$ & 21.9 & 0.0 & $10.3 \pm 1.7$ & 7 & $3.9 \pm 0.4$ & $45.2 \pm 4.5$ \\
\hline HillTop & 2001 & M & $80.6 \pm 4.1$ & 22.9 & 0.1 & $13.3 \pm 2.2$ & 15 & $2.8 \pm 0.4$ & $47.3 \pm 2.9$ \\
\hline Carmody West & 2001 & $\mathrm{P}$ & $96.0 \pm 1.1$ & 22.7 & 0.0 & $14.5 \pm 2.9$ & 8 & $2.5 \pm 0.4$ & $44.6 \pm 4.8$ \\
\hline Dukes West & 2001 & M & $87.1 \pm 3.7$ & 27.4 & 0.1 & $16.3 \pm 3.7$ & 10 & $5.2 \pm 0.2$ & $32.7 \pm 2.3$ \\
\hline Carmody East & 2001 & M & $79.8 \pm 6.4$ & 19.1 & 0.1 & $23.9 \pm 3.6$ & 11 & $2.1 \pm 0.4$ & $60.1 \pm 4.6$ \\
\hline Monette & 2001 & M & $96.4 \pm 2.5$ & 24.8 & 0.1 & $27.1 \pm 2.6$ & 8 & $2.2 \pm 0.3$ & $50.1 \pm 6.4$ \\
\hline SuperThick & 2001 & M & $76.5 \pm 4.5$ & 16.4 & 0.0 & $28.3 \pm 3.1$ & 14 & $2.5 \pm 0.4$ & $47.2 \pm 2.8$ \\
\hline Chatham Ski Hill & 2001 & M & $93.8 \pm 2.2$ & 22.6 & 5.3 & $43.6 \pm 2.5$ & 18 & $2.7 \pm 0.3$ & $47.7 \pm 3.7$ \\
\hline Section 28 & 2001 & M & $86.4 \pm 4.8$ & 17.1 & 0.1 & $45.1 \pm 2.7$ & 13 & $1.4 \pm 0.2$ & $60.6 \pm 8.4$ \\
\hline Miners NE & 2001 & M & $88.7 \pm 3.3$ & 15.6 & 0.5 & $52.6 \pm 2.6$ & 11 & $1.9 \pm 0.3$ & $60.2 \pm 5.9$ \\
\hline Miners Control & 2002 & $\mathrm{P}$ & $96.3 \pm 2.2$ & 36.3 & 0.0 & $0.0 \pm 0.0$ & 4 & $3.5 \pm 0.7$ & $21.4 \pm 3.0$ \\
\hline Abe Lk. & 2002 & M & $91.1 \pm 2.0$ & 25.1 & 3.1 & $3.8 \pm 1.4$ & 4 & $4.0 \pm 0.7$ & $33.8 \pm 4.2$ \\
\hline Munising Ski Hill & 2002 & M & $95.2 \pm 2.6$ & 10.6 & 9.5 & $7.5 \pm 2.4$ & 3 & $3.8 \pm 0.8$ & $38.1 \pm 8.4$ \\
\hline Miller Road & 2002 & M & $86.9 \pm 3.2$ & 25.3 & 0.0 & $12.4 \pm 4.0$ & 6 & $3.3 \pm 0.5$ & $39.3 \pm 6.7$ \\
\hline Perch Lk. North & 2002 & M & $96.7 \pm 1.8$ & 14.2 & 8.5 & $15.6 \pm 2.5$ & 12 & $3.4 \pm 0.4$ & $43.4 \pm 5.1$ \\
\hline HW Island & 2002 & M & $85.7 \pm 3.4$ & 19.9 & 0.2 & $22.2 \pm 2.9$ & 9 & $2.5 \pm 0.4$ & $50.4 \pm 6.0$ \\
\hline PIRO & 2002 & $\mathrm{P}$ & $96.3 \pm 1.3$ & 29.1 & 0.1 & $24.4 \pm 3.9$ & 9 & $3.3 \pm 0.4$ & $45.4 \pm 5.7$ \\
\hline 553 & 2002 & M & $94.3 \pm 2.5$ & 21.3 & 0.7 & $24.8 \pm 5.0$ & 5 & $3.8 \pm 0.7$ & $58.6 \pm 4.7$ \\
\hline $\mathrm{H}-58$ & 2002 & M & $89.9 \pm 2.0$ & 21.9 & 0.1 & $27.5 \pm 4.1$ & 6 & $2.6 \pm 0.4$ & $47.3 \pm 8.8$ \\
\hline Perch Lk. East & 2002 & M & $85.2 \pm 2.4$ & 14.2 & 1.8 & $31.3 \pm 3.5$ & 9 & $1.6 \pm 0.2$ & $45.4 \pm 5.3$ \\
\hline Big Tree & 2002 & M & $91.7 \pm 2.5$ & 22.5 & 0.1 & $32.3 \pm 4.3$ & 8 & $1.7 \pm 0.4$ & $59.0 \pm 10.6$ \\
\hline Miners Basin & 2002 & M & $93.3 \pm 1.9$ & 26.7 & 0.0 & $45.1 \pm 3.2$ & 9 & $1.7 \pm 0.3$ & $52.1 \pm 4.2$ \\
\hline Miners North & 2002 & M & $85.7 \pm 5.8$ & 22.8 & 0.7 & $54.4 \pm 4.3$ & 8 & $2.0 \pm 0.3$ & $49.7 \pm 3.7$ \\
\hline
\end{tabular}

${ }^{a}$ Management status of forest stand; P: protected area, M: managed forest.

${ }^{b}$ Number of clusters of sampled yew stems with $\geq 3$ live stems.

categories (Figure 4); clusters of stems at the edge of or in the interior of discrete yew patches were less likely to contain at least one dead stem than for stems not in patches.

Deer pellet counts confirmed that winter deer densities were low for all study stands; that is, the number of pelletgroups $/ 400 \mathrm{~m}^{2}$ observed at each of the sites was less than the 6.75 pellet-groups $/ 400 \mathrm{~m}^{2}$ value used to represent deer densities of $\sim 2-6 / \mathrm{km}^{2}$ [17]. The mean number of pelletgroups $/ 400 \mathrm{~m}^{2}( \pm \mathrm{SE})$ for all stands combined was $1.7( \pm 0.1)$.

The global model fit the data well based on the goodnessof-fit analysis $\left(X^{2}=148.7, \mathrm{df}=12, P<0.001\right.$; Olsson 2002). Model 2, the single variable model for patch location (LOC; Table 2), had a $49 \%$ likelihood of being the best model in the initial 10-model set. Parameter estimates for patch location indicated that browsing intensity was greatest for isolated clusters of stems, intermediate for clusters at the edge of Canada yew patches, and least for clusters greater than $1 \mathrm{~m}$ from the edge. Models 3 and 4, which included both mean stem length and patch location, were also supported with $\Delta$ QAIC $_{c}$ scores of $<2$. However, for Model 3, 95\% confidence intervals for the parameter estimate for mean stem length (LENGTH) included zero, suggesting that patch location was driving model results. The global model and Model 9, the single variable model of percent Canada yew cover in the stand, were less supported ( $\triangle \mathrm{QAIC}_{c}$ scores between 4 and 8 ). All other models were poorly supported, with $\Delta \mathrm{QAIC}_{c}>25$.

A post hoc analysis of model parameters suggested that even though the single variable model that included percent cover (YEWCOV) did not perform well against Models 2-4, it was the next ranked model in the model set and the $95 \%$ confidence intervals for the YEWCOV parameter estimate did not include zero. If included in a model with patch location (LOC), overall predictive power might be increased. Therefore, two extra models were added to the model set: a two-variable model with patch location (LOC) and percent cover (YEWCOV) and a three-variable model with patch location, percent yew cover, and an interaction term (LOC ${ }^{*}$ YEWCOV). This post hoc analysis demonstrated that Model 11 was overwhelmingly the best model in the new set $\left(\mathrm{QAIC}_{c}\right.$ weight of 0.91 ; Table 2 ). No other model had a 
TABLE 2: Model selection results from analysis of white-tailed deer browsing intensity on Canada yew in relation to local and site-level factors in northern/mixed hardwood forests in the Upper Peninsula, Michigan, 2001-2002. A post hoc model selection analysis was conducted after results from the a priori exercise suggested model fit could be improved.

\begin{tabular}{|c|c|c|c|c|c|c|c|c|c|c|c|c|c|c|}
\hline \multirow{2}{*}{ Model } & \multirow{2}{*}{ Predictors } & \multirow{2}{*}{ Parameter } & \multirow{2}{*}{ LCI } & \multirow{2}{*}{ UCI } & \multirow{2}{*}{$k$} & \multirow{2}{*}{ Deviance } & \multicolumn{4}{|c|}{ A priori } & \multicolumn{4}{|c|}{ Post hoc } \\
\hline & & & & & & & $\mathrm{QAIC}_{c}$ & $\Delta_{i}$ & Rank & Weight & $\mathrm{QAIC}_{c}$ & $\Delta_{i}$ & Rank & Weight \\
\hline \multirow{2}{*}{1} & INTERCEPT & 3.7407 & 2.9895 & 4.4919 & \multirow{2}{*}{3} & \multirow{2}{*}{380.46} & \multirow{2}{*}{530.76} & \multirow{2}{*}{25.70} & \multirow{2}{*}{6} & \multirow{2}{*}{0.00} & \multirow{2}{*}{530.76} & \multirow{2}{*}{36.05} & \multirow{2}{*}{8} & 0.00 \\
\hline & LENGTH & -0.0222 & -0.0325 & -0.0119 & & & & & & & & & & 0.00 \\
\hline & INTERCEPT & 1.7033 & 14.4577 & 1.9488 & & & & & & & & & & \\
\hline 2 & LOC (1) & 2.0034 & 1.4081 & 2.5988 & 5 & 312.74 & 505.06 & 0.00 & 1 & 0.49 & 505.06 & 10.35 & 4 & 0.01 \\
\hline & LOC (2) & 0.8835 & 0.6398 & 1.1272 & & & & & & & & & & \\
\hline & INTERCEPT & 1.8983 & 1.4834 & 2.3132 & & & & & & & & & & \\
\hline 3 & LENGTH & -0.0033 & -0.0096 & 0.0030 & 6 & 312.19 & 506.92 & 1.86 & 3 & 0.19 & 506.92 & 12.20 & 6 & 0.00 \\
\hline$J$ & LOC (1) & 1.9150 & 1.3254 & 2.5046 & & & & & & & & & & \\
\hline & $\operatorname{LOC}(2)$ & 0.8506 & 0.6014 & 1.0998 & & & & & & & & & & \\
\hline & INTERCEPT & 2.7588 & 2.2187 & 3.2989 & & & & & & & & & & \\
\hline 4 & LENGTH* $^{*}$ LOC (1) & 0.0280 & 0.0109 & 0.0451 & 5 & 315.41 & 506.36 & 1.30 & 2 & 0.26 & 506.36 & 11.65 & 5 & 0.00 \\
\hline & LENGTH* LOC (2) & -0.0040 & -0.0130 & 0.0049 & & & & & & & & & & \\
\hline & INTERCEPT & 2.7617 & 2.0863 & 3.4371 & & & & & & & & & & \\
\hline & SLOPE (E) & -0.7394 & -1.6222 & 0.1433 & & & & & & & & & & \\
\hline 5 & SLOPE (LEVEL) & -0.1012 & 0.4036 & -0.8922 & 7 & 407.62 & 549.71 & 44.65 & 10 & 0.00 & 549.71 & 55.01 & 12 & 0.00 \\
\hline & SLOPE $(\mathrm{N})$ & 0.4383 & -0.4976 & 1.3743 & & & & & & & & & & \\
\hline & SLOPE (S) & 0.1383 & -0.5895 & 0.8662 & & & & & & & & & & \\
\hline 6 & INTERCEPT & 1.5243 & 0.2587 & 2.7900 & 3 & 409.24 & 541.88 & 36.82 & 9 & & 541.88 & 47.17 & 11 & 0.00 \\
\hline 0 & CANOPY & 0.0131 & -0.0004 & 0.0267 & 3 & 409.24 & 341.88 & 30.82 & 9 & 0.00 & 541.88 & 47.17 & 11 & 0.00 \\
\hline 7 & INTERCEPT & 3.4921 & 3.1468 & 3.8374 & 4 & 40198 & 541.23 & 36.17 & 7 & 0.00 & 541.23 & 4652 & 10 & 0.00 \\
\hline 7 & CONIFER (1) & -0.8855 & -1.3771 & -0.3938 & & & & & & & & & & \\
\hline & INTERCEPT & 2.4838 & 1.0486 & 3.9190 & & & & & & & & & & \\
\hline 8 & CANOPY & 0.0107 & -0.0029 & 0.0243 & 5 & 397.90 & 541.77 & 36.71 & 8 & 0.00 & 541.77 & 47.06 & 9 & 0.00 \\
\hline & CONIFER (1) & -0.8184 & -1.3294 & -0.3075 & & & & & & & & & & \\
\hline 9 & INTERCEPT & 3.8626 & 3.2372 & 4.4881 & 3 & 337.42 & 512.46 & 7.40 & 5 & 0.01 & 512.46 & 17.76 & 7 & 0.00 \\
\hline 9 & YEWCOV & -0.0425 & -0.0607 & -0.0243 & 3 & & & & & & & & & \\
\hline & INTERCEPT & 1.6726 & 0.0513 & 3.2939 & & & & & & & & & & \\
\hline & LENGTH & 0.0002 & -0.0120 & 0.0125 & & & & & & & & & & \\
\hline & LOC (1) & 0.5431 & -0.8939 & 1.9800 & & & & & & & & & & \\
\hline & LOC $(2)$ & 0.8426 & -0.2707 & 1.9559 & & & & & & & & & & \\
\hline & LENGTH* LOC (1) & 0.0292 & -0.0019 & 0.0604 & & & & & & & & & & \\
\hline & LENGTH $^{*}$ LOC (2) & -0.0043 & -0.0220 & 0.0134 & & & & & & & & & & \\
\hline 10 & SLOPE (E) & -0.4194 & -1.4496 & 0.6108 & 18 & 266.08 & 509.76 & 4.70 & 4 & 0.05 & 509.76 & 15.05 & 3 & 0.00 \\
\hline & SLOPE (LEVEL) & 0.1925 & -0.3621 & 0.7470 & & & & & & & & & & \\
\hline & SLOPE $(\mathrm{N})$ & -0.0014 & -0.7242 & 0.7215 & & & & & & & & & & \\
\hline & SLOPE (S) & 0.1482 & -0.5265 & 0.8230 & & & & & & & & & & \\
\hline & CANOPY & 0.0163 & 0.0065 & 0.0261 & & & & & & & & & & \\
\hline & CONIFER (1) & -0.5958 & -1.1676 & -0.0240 & & & & & & & & & & \\
\hline & YEWCOV & -0.0271 & -0.0400 & -0.0143 & & & & & & & & & & \\
\hline & INTERCEPT & 2.6906 & 2.1004 & 3.2809 & & & & & & & & & & \\
\hline 11 & LOC (1) & 1.5258 & 0.9015 & 2.1502 & 6 & 288.17 & na & na & na & na & 494.71 & 0.00 & 1 & 0.91 \\
\hline 11 & LOC (2) & 0.6323 & 0.3750 & 0.8897 & & & & & & & & & & \\
\hline & YEWCOV & -0.0265 & -0.0420 & -0.0109 & & & & & & & & & & \\
\hline
\end{tabular}


TABLE 2: Continued.

\begin{tabular}{|c|c|c|c|c|c|c|c|c|c|c|c|c|c|c|}
\hline \multirow{2}{*}{ Model } & \multirow{2}{*}{ Predictors } & \multirow{2}{*}{ Parameter } & \multirow{2}{*}{ LCI } & \multirow{2}{*}{ UCI } & \multirow{2}{*}{$k$} & \multirow{2}{*}{ Deviance } & \multicolumn{4}{|c|}{ A priori } & \multicolumn{4}{|c|}{ Post hoc } \\
\hline & & & & & & & $\mathrm{QAIC}_{c}$ & $\Delta_{i}$ & Rank & Weight & $\mathrm{QAIC}_{c}$ & $\Delta_{i}$ & Rank & Weight \\
\hline \multirow{6}{*}{12} & INTERCEPT & 2.2263 & 1.3067 & 3.1459 & \multirow{6}{*}{9} & \multirow{6}{*}{285.16} & \multirow{6}{*}{ na } & \multirow{6}{*}{ na } & \multirow{6}{*}{ na } & \multirow{6}{*}{ na } & \multirow{6}{*}{499.60} & \multirow{6}{*}{4.89} & \multirow{6}{*}{2} & \multirow{6}{*}{0.08} \\
\hline & LOC (1) & 1.8630 & 0.5694 & 3.1566 & & & & & & & & & & \\
\hline & LOC (2) & 1.3375 & 0.4074 & 2.2676 & & & & & & & & & & \\
\hline & YEWCOV & -0.0140 & -0.0344 & 0.0064 & & & & & & & & & & \\
\hline & LOC $(1)^{*}$ YEWCOV & -0.0058 & -0.0496 & 0.0379 & & & & & & & & & & \\
\hline & LOC $(2)^{*}$ YEWCOV & -0.0211 & -0.0448 & 0.0027 & & & & & & & & & & \\
\hline
\end{tabular}

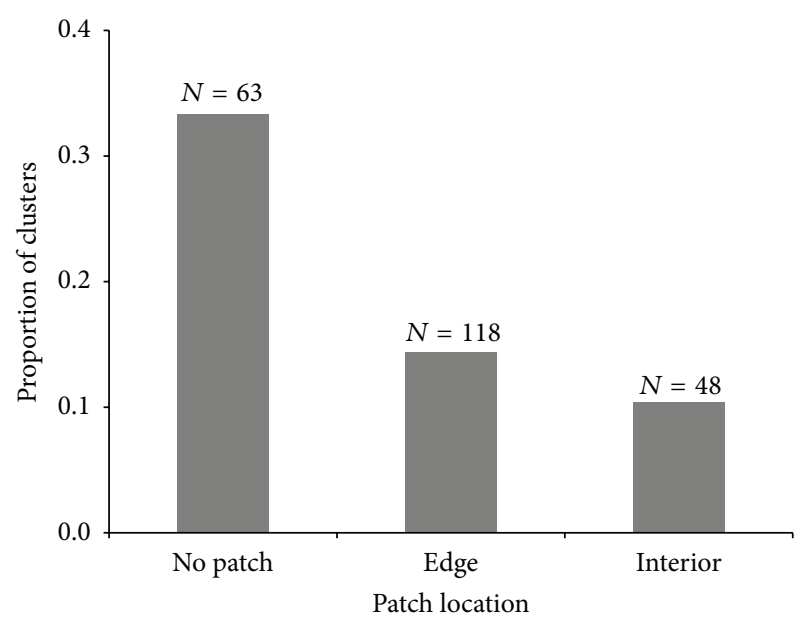

Figure 4: Proportion of sampled Canada yew clusters containing $\geq 1$ dead stems in relation to distance from yew patch edge from 24 stands in Marquette and Alger counties, MI, 2001-2002. Only those clusters with 5 Canada yew stems were included in analysis. Numbers above each category represent total number of clusters sampled.

$\mathrm{QAIC}_{c}<4$. Parameter estimates for the variables LOC and YEWCOV suggest that two forces are acting independently to affect browsing intensity on clusters of Canada yew stems at two spatial scales. A model term measuring interaction between these two factors was not in the top-ranked model, suggesting that these factors operate independently. Variable importance weights for all variables in the post hoc model set (calculated as the sum of $\mathrm{QAIC}_{c}$ weights for each model in which the predictor appears) suggest that LOC (1.000) and YEWCOV (0.990) are equally important in affecting browsing intensity. All other variables, including LENGTH, had variable importance weights less $<0.079$ and therefore had relatively less effect on browsing intensity. At the intermediate scale (or a scale representing within-stand heterogeneity), location of stems within a patch affected browsing intensity. In relation to stems in the interior of patches $(>1 \mathrm{~m}$ from edge), mean browsing score was 0.63 units higher for stems at the edge of Canada yew patches and 1.53 units higher for stems not associated with patches. At the stand scale, mean browsing score decreased 0.27 units for every $10 \%$ increase in stand-level Canada yew cover.

\section{Discussion}

Browsing intensity on Canada yew in this study was related to two factors operating independently at two spatial scales: a local-scale pattern in which deer browsing intensity was the least in the interior of Canada yew patches and a stand-scale pattern in which browsing intensity decreased linearly with increasing amount of Canada yew cover. The local scale pattern we observed is consistent with observations in northern Wisconsin where deer appeared to focus browsing activity on stems immediately adjoining deer trails bisecting large patches of Canada yew, eventually widening and creating new trails over a period of years until nearly all Canada yew within the patch was heavily browsed (J. Meeker, personal comments). Hester and Baillie [24] observed similar patterns of browsing on heather (Calluna vulgaris) by domestic sheep (Ovis aries) and red deer (Cervus elaphus) in Scotland, where browsing was focused almost exclusively within $3 \mathrm{~m}$ of the edge of heather patches by both species and the gradual expansion of trails eventually resulted in increased fragmentation of existing heather patches.

Canada yew is considered the most preferred browse item by deer in the Great Lakes states, so much so that it is often browsed disproportionately more than other highly preferred browse items such as white cedar (Thuja occidentalis) [12, 18]. However, despite its high preference by deer, it may be energetically expensive for deer to penetrate deeply into dense or wide patches of Canada yew to browse. Canada yew's propensity to reproduce by layering produces roughly circular-shaped patches comprised of dense tangles of intermingling stems; this patchy growth form is especially evident in high-density areas with large individuals [13]. Mean height and length of stems in most discrete patches of Canada yew observed in this study were greater than $40 \mathrm{~cm}$ and $55 \mathrm{~cm}$, respectively (S. Windels, unpublished data). Based on models derived from travel through snow, Parker et al. [20] estimated that energetic costs expended by elk and mule deer to travel through slash increased with increasing height and density of the slash piles (but see [21]). We suggest that Canada yew's patchy growth form may physically inhibit deer penetration into patches of yew $>2 \mathrm{~m}$ in diameter, thus creating a refugia to browsing deer in the interior of these patches. Examples of physical refugia are relatively common in plantungulate systems (e.g., $[25,26])$. However, we are unaware of other instances of physical refugia created by individuals of the same species. Allison $[13,27]$ demonstrated that 
white-tailed deer can directly and indirectly affect sexual reproduction in Canada yew, a wind-pollinated species. The refugia created by dense patches of Canada yew may act as seed and pollen sources for Canada yew populations subjected to deer browsing.

The pattern of decreasing browsing intensity on Canada yew stems as Canada yew abundance increased at the stand scale is consistent with a Holling Type II functional response as described by Noy-Meir [28]. Windels and Flaspohler [8] observed a similar negative relationship of deer browsing intensity with abundance of Canada yew on individual islands in the Apostle Islands archipelago in Lake Superior. This Type II response has also been observed in other plant-herbivore systems, including white-tailed deer and nettle (Laportea canadensis) [29], ground squirrels (Spermophilus parryii) and lupine (Lupinus arcticus) [22]. Under a uniform deer density (or number of deer-use days) and therefore uniform level of absolute biomass consumption, the amount of impact per stem is reduced as density (cover) increases. In our study, this pattern was not observed temporally within a stand but was apparent across the entire set of study stands sampled.

A Type II functional response also theoretically allows for two alternate stable states of plant abundance under a constant herbivore density [29]. In our study system, Canada yew would be extirpated when its abundance at the sitelevel falls below some threshold value. That is, over time Canada yew will be extirpated when the amount of biomass removed annually by deer exceeds the amount of biomass produced at the site level. Above the threshold value, the amount of browse removed by deer does not exceed the amount produced and Canada yew abundance increases over time. Under the very low deer densities in our study area, we believe that this theoretical threshold occurs between 15 and $30 \%$ areal cover for stands in the snow belt of the Lake Superior Watershed. For many of the stands sampled with $<15 \%$ cover of Canada yew, the mean browsing score approached 4 , which equates to $50-75 \%$ of its available twigs browsed. These stands also had proportionally more dead stems in the sample clusters (S. Windels, unpublished data), suggesting that deer browsing was exceeding the capacity of the Canada yew population to maintain itself. Conversely, all of the stands in our study area with Canada yew cover $>30 \%$ appeared vigorous and relatively unaffected by browsing.

There are two larger scale trends, outside the scope of our original objectives, that likely affect the threshold of cover we observed. First, white-tailed deer densities throughout the Great Lakes region are generally increasing [30, 31]. Second, climate change predictions for the Great Lakes region suggest trends towards milder winters with less lake-effect snowfall [32]. Early snowfall events often cover yew stems and protect them from browsing. Deep snows also force some deer populations to migrate to traditional deer yards and away from upland areas containing Canada yew. A change in the timing or amount of annual snowfall therefore may expose Canada to deer browsing for more days in the late fall/early winter browsing period. Together, these trends suggest that the total number of deer use days will increase within the Lake
Superior Watershed. Increased use of coastal forests by whitetailed deer may shift the threshold towards a higher value of Canada yew cover.

A complete understanding of the stand-level relationship we describe is complicated by the apparent physical barrier to stem access that large diameter patches may provide. The effect of decreasing browse pressure with distance from a patch edge we observed reduces the amount of Canada yew available to browsing deer below what is present at the site. Further, as patch radius increases, the ratio of edge (i.e., the area of the outer portion of circular patch most susceptible to browsing) to the total area of the patch decreases (logarithmically for a circular patch) so that only a fraction of the total patch would be most susceptible to browsing by deer. Total cover of Canada yew at the site level is basically comprised of the sum of the cover of individual patches. For illustrative purposes, if we assume a constant average patch size as Canada yew ground cover increases within a site, the amount of patch edge susceptible to browsing would be linearly related to total Canada yew cover. However, if average patch size increases as Canada yew cover increases within a site, then the amount of patch edge would increase logarithmically as Canada yew cover increases. In either case, a site with a high abundance of Canada yew made up of many small patches would be more susceptible to browsing by deer than a high-abundance site made up of a smaller number of large patches.

\section{Conclusions}

White-tailed deer have been implicated as one of the main drivers in the dramatic decline in range and importance of Canada yew in forest understories in the Eastern United States. Results from our study suggest that intensity of deer browsing on Canada yew in the Lake Superior Watershed was affected by two factors operating independently at two spatial scales relevant to white-tailed deer. Our results suggest that as the size of individual Canada yew patches increases, the likelihood of the patch persisting under a constant deer browsing pressure also increases. Moreover, we speculate that the extirpation of Canada yew from a stand occurs on a patch-by-patch basis rather than a steady decline across all stems within a stand. As stems at the edges of patches gradually die from heavy browsing, functional patch size decreases and new stems nearer the interior become susceptible to browsing. Due to the logarithmic relationship between amount of edge and area of a circular patch, the rate at which patches shrink from chronic intensive browsing accelerates as patch size decreases until this "death spiral" culminates in the functional loss of that patch from the site. Further, stands with a greater abundance of Canada yew browse are also more likely to persist than stands with lower abundance. Though we did not find a significant interaction between these two factors in our models, intuitively stands containing only small patches of Canada yew should be more prone to local extirpation than stands containing mostly large patches.

Our study stands were all located within zones of traditionally low white-tailed deer density, and maximum snow depth during this study was close to or above 
long-term averages. However, it is unknown if the patterns and processes of deer-induced Canada yew decline we observed are found elsewhere in Canada yew's range. Future research should examine scale-dependent deer browsing patterns on Canada yew under higher deer densities.

\section{Acknowledgments}

The authors thank R. Posey, A. Kavalunas, D. Oberg, M. Potvin, and A. Chouinard for assistance with field work. Assistance with study site selection and site access was provided by J. Belant (Pictured Rocks National Lakeshore), K. Doran (Hiawatha National Forest), and M. Wilk (Shelter Bay Forests). The authors thank C. Huckins, B. McLaren, J. Meeker, L. Nagel, and C. Webster for comments that improved earlier drafts. This research was supported by The Nature Conservancy of Michigan, Michigan Department of Natural Resources Natural Heritage Program, Michigan Technological University's Graduate School and the Department of Forest Resources and Environmental Science, and the U.S. National Park Service.

\section{References}

[1] R. L. Senft, M. B. Coughenour, D. W. Bailey, L. R. Rittenhouse, O. E. Sala, and D. M. Swift, "Large herbivore foraging and ecological hierarchies," BioScience, vol. 37, no. 11, pp. 789-799, 1987.

[2] M. R. Bergman, G. R. Iason, and A. J. Hester, "Feeding patterns by roe deer and rabbits on pine, willow and birch in relation to spatial arrangement," Oikos, vol. 109, no. 3, pp. 513-520, 2005.

[3] J. Månsson, H. Andrén, Å. Pehrson, and R. Bergström, "Moose browsing and forage availability: a scale-dependent relationship?" Canadian Journal of Zoology, vol. 85, no. 3, pp. 372-380, 2007.

[4] J. Pastor, B. Dewey, R. J. Naiman, P. F. McInnes, and Y. Cohen, "Moose browsing and soil fertility in the boreal forests of Isle Royale National Park," Ecology, vol. 74, no. 2, pp. 467-480, 1993.

[5] D. M. Waller and W. S. Alverson, "The white-tailed deer: a keystone herbivore," Wildlife Society Bulletin, vol. 25, no. 2, pp. 217-226, 1997.

[6] D. J. Augustine and S. J. McNaughton, "Ungulate effects on the functional species composition of plant communities: herbivore selectivity and plant tolerance," The Journal of Wildlife Management, vol. 62, no. 4, pp. 1165-1183, 1998.

[7] D. W. Bailey, J. E. Gross, E. A. Laca et al., "Mechanisms that result in large herbivore grazing distribution patterns," Journal of Range Management, vol. 49, no. 5, pp. 386-400, 1996.

[8] S. K. Windels and D. J. Flaspohler, "The ecology of Canada yew (Taxus canadensis marsh.): a review," Botany, vol. 89, no. 1, pp. $1-17,2011$.

[9] S. K. Windels and D. J. Flaspohler, "Considerations for conservation and restoration of Canada yew in protected areas," Natural Areas Journal. In press.

[10] D. Kingston, "Taxol and its analog," in Anticancer Agents From Natural Products, G. M. Cragg, D. G. I. Kingston, and D. J. Newman, Eds., pp. 89-122, CRC \& Taylor \& Francis, Boca Raton, Fla, USA, 2005.

[11] A. Leopold, L. K. Sowls, and D. L. Spencer, "A survey of overpopulated deer ranges of the United States," The Journal of Wildlife Management, vol. 11, no. 2, pp. 163-177, 1947.
[12] E. W. Beals, G. Cottam, and R. J. Vogl, "Influence of deer on vegetation of the Apostle Islands, wisconsin," The Journal of Wildlife Management, vol. 24, no. 1, pp. 68-80, 1960.

[13] T. D. Allison, "The influence of deer browsing on the reproductive biology of Canada yew (Taxus canadensis marsh.)-I. Direct effect on pollen, ovule, and seed production," Oecologia, vol. 83, no. 4, pp. 523-529, 1990.

[14] J. J. Stachowicz and T. D. Allison, "Vegetation, browsing, and site factors as determinants of Canada yew distribution in central new hampshire," Rhodora, vol. 97, pp. 357-374, 1995.

[15] W. S. Alverson and D. M. Waller, "Deer populations and the widespread failure of hemlock regeneration in northern forests," in The Science of Overabundance: Deer Ecology and Population Management, W. J. McShea, H. B. Underwood, and J. H. Rappole, Eds., pp. 280-297, Smithsonion Institution Press, Washington, DC, USA.

[16] National Weather Service Marquette Weather Forecast Office, National Oceanic and Atmospheric Organization, Negaunee, Mich, USA, http://www.crh.noaa.gov/mqt/normals/marquette.php.

[17] M. J. Potvin, T. D. Drummer, J. A. Vucetich, D. E. Beyer Jr., R. O. Peterson, and J. H. Hammill, "Monitoring and habitat analysis for wolves in upper Michigan," The Journal of Wildlife Management, vol. 69, no. 4, pp. 1660-1669, 2005.

[18] D. R. King, Deer and hare population-range relationships on garden and south fox islands, [Ph.D. thesis], University of Michigan, Ann Arbor, Mich, USA, 1970.

[19] K. P. Burnham and D. R. Anderson, Model Selection And Multimodel Inference: A Practical Information-Theoretic Approach, Springer, New York, NY, USA, 2nd edition, 2002.

[20] K. L. Parker, C. T. Robbins, and T. A. Hanley, "Energy expenditures for locomotion by mule deer and elk," The Journal of Wildlife Management, vol. 48, no. 2, pp. 474-488, 1984.

[21] J. D. Forester, D. P. Anderson, and M. G. Turner, "Do highdensity patches of coarse wood and regenerating saplings create browsing refugia for aspen (Populus tremuloides Michx.) in Yellowstone National Park (USA)?" Forest Ecology and Management, vol. 253, no. 1-3, pp. 211-219, 2007.

[22] L. Frid and R. Turkington, "The influence of herbivores and neighboring plants on risk of browsing: a case study using arctic lupine (Lupinus arcticus) and arctic ground squirrels (Spermophilus parryii plesius)," Canadian Journal of Zoology, vol. 79, no. 5, pp. 874-880, 2001.

[23] H. J. Vivas and B. E. Saether, "Interactions between a generalist herbivore, the moose Alces alces, and its food resources: an experimental study of winter foraging behaviour in relation to browse availability," Journal of Animal Ecology, vol. 56, no. 2, pp. 509-520, 1987.

[24] A. J. Hester and G. J. Baillie, "Spatial and temporal patterns of heather use by sheep and red deer within natural heather/grass mosaics," Journal of Applied Ecology, vol. 35, no. 5, pp. 772-784, 1998.

[25] K. L. Borgmann, D. M. Waller, and T. P. Rooney, "Does balsam fir (Abies balsamea) facilitate the recruitment of eastern hemlock (Tsuga canadensis)?" American Midland Naturalist, vol. 141, no. 2, pp. 391-397, 1999.

[26] D. García, R. Zamora, J. A. Hódar, J. M. Gómez, and J. Castro, "Yew (Taxus baccata L.) regeneration is facilitated by fleshyfruited shrubs in Mediterranean environments," Biological Conservation, vol. 95, no. 1, pp. 31-38, 2000.

[27] T. D. Allison, "The influence of deer browsing on the reproductive biology of Canada yew (Taxus canadensis marsh.)-II. Pollen 
limitation: an indirect effect," Oecologia, vol. 83, no. 4, pp. 530534, 1990.

[28] I. Noy-Meir, "Stability in grazing systems: an application of predator graphs," Journal of Ecology, vol. 63, no. 2, pp. 459-481, 1975.

[29] D. J. Augustine, L. E. Frelich, and P. A. Jordan, "Evidence for two alternate stable states in an ungulate grazing system," Ecological Applications, vol. 8, no. 4, pp. 1260-1269, 1998.

[30] T. R. McCabe and R. E. McCabe, "Recounting whitetails past," in The Science of Overabundance: Deer Ecology and Population Management, W. J. McShea, H. B. Underwood, and J. H. Rappole, Eds., pp. 11-26, Smithsonian Institution Press, Washington DC, USA, 1997.

[31] T. P. Rooney, S. L. Solheim, and D. M. Waller, "Factors affecting the regeneration of northern white cedar in lowland forests of the Upper Great Lakes region, USA," Forest Ecology and Management, vol. 163, no. 1-3, pp. 119-130, 2002.

[32] K. E. Kunkel, N. E. Westcott, and D. A. R. Kristovich, "FOCUS: climate change and lake-effect snow," in Preparing for A Changing Climate: the Potential Consequences of Climate Variability and Change, P. J. Sousounis and J. M. Bisanz, Eds., Great Lakes Regional Assessment Group, 2000. 

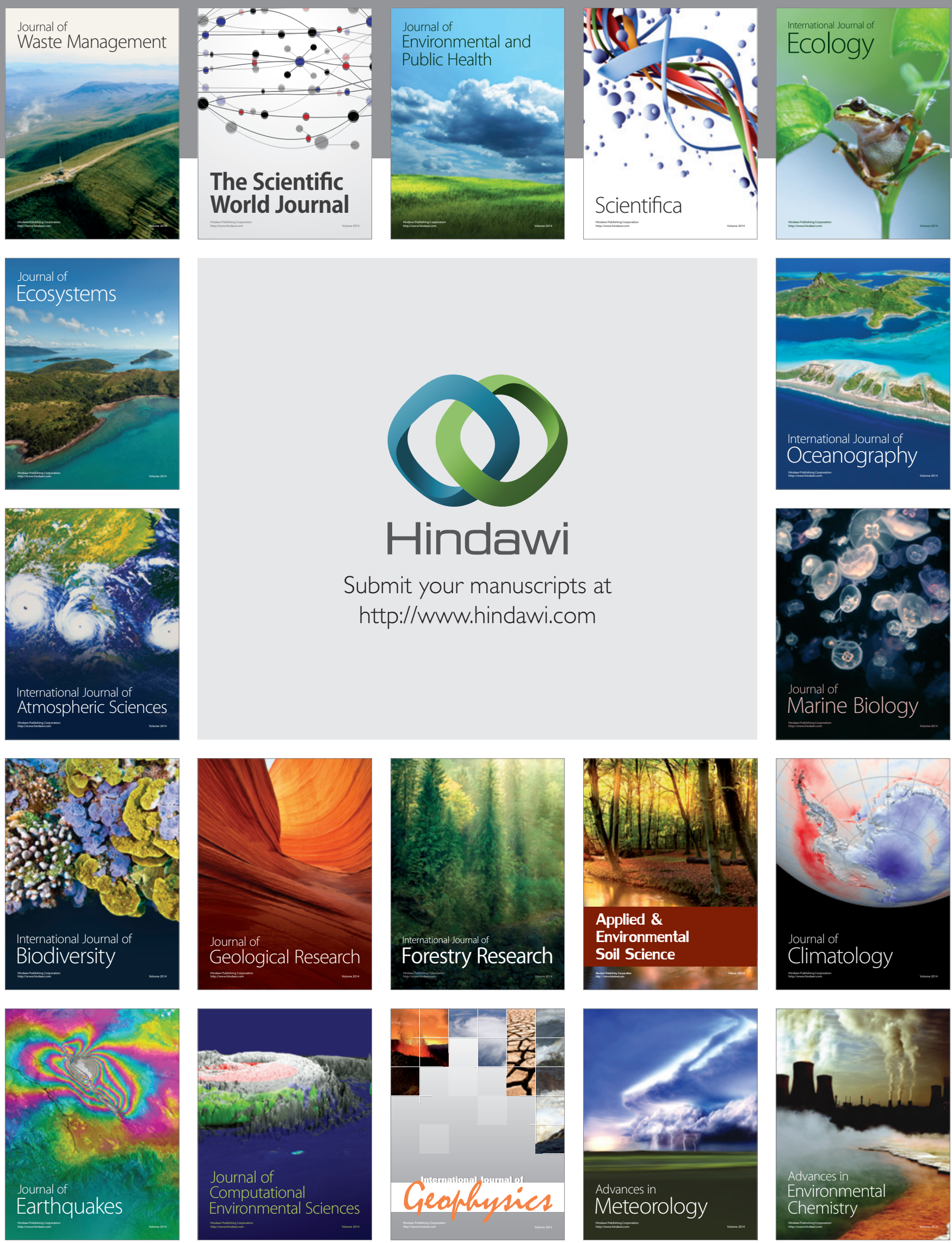